\title{
Investigations of the synergistic enhancement of antimicrobial activity in mixtures of magainin 2 and PGLa
}

\author{
Elise Glattard\#, Evgeniy S. Salnikov\#, Christopher Aisenbrey and Burkhard \\ Bechinger*
}

\#equal contributions by these authors
Université de Strasbourg / CNRS, UMR7177, Institut de Chimie, 4, rue Blaise Pascal, 67070 Strasbourg, France
* corresponding author: Burkhard Bechinger
Faculté de chimie, Institut le Bel, 4, rue Blaise Pascal, 67070 Strasbourg, France Tel.: +33 3688513 03, FAX: +33 3688517 35, bechinger@unistra.fr

Keywords: amphipathic helix, antimicrobial activities, membrane topology, peptide-lipid interactions, solid-state NMR, supported lipid bilayer.

Running title: Magainin synergistic interactions 


\begin{abstract}
:
Magainins are antimicrobial peptides isolated from the African clawed frog Xenopus laevis. They interact with bacterial membranes where they cause channel formation and membrane disruption. When added as a cocktail magainin 2 and PGLa are considerably more efficient when compared to the corresponding amounts of individual components. In order to investigate this synergistic interaction of PGLa and magainin a number of magainin variants have been prepared and investigated in biological and biophysical assays. In particular we report on the antimicrobial activities and solid-state NMR investigations of magainins that have been extended by a carboxyterminal GGC tripeptide to form covalently linked dimers. Notably, when the formation of the covalent linkage is prevented by exchanging the cystein by serine or alanine no loss in efficiency was observed indicating that the covalent interaction is not necessary for synergistic interaction. In a next step peptides labelled with ${ }^{15} \mathrm{~N}$ and ${ }^{2} \mathrm{H}$ were reconstituted into oriented membranes and their topology studied by solid-state NMR spectroscopy. The tendency of some of these peptides to adopt membrane-spanning alignments does not correlate with their synergistic activities in antimicrobial assays. In contrast, the stable alignment of PGLa parallel to the surface of membranes made of $E$. coli lipid extracts is strongly suggestive that the peptides develop synergistic activities when in an in-planar configuration. Notably, the phospholipid head groups these samples show a high degree of disturbance suggesting that the synergistic interactions between the magainin peptides could be mediated through the lipid phase.
\end{abstract}




\section{LIST OF ABBREVIATIONS}

CI: combination index

di-C10:0-PC: 1, 2-didecanoyl-sn-glycero-3-phosphocholine

DMPC: 1, 2-dimyristoyl-sn-glycero-3-phosphocholine

DMPG: 1, 2-dimyristoyl-sn-glycero-3-phospho-(1'-rac-glycerol)

ITC: Isothermal titration calorimetry

$\mathrm{MIC}_{\mathrm{n}}$ : minimal concentration to inhibit $\mathrm{n} \%$ of bacterial growth

MH: Mueller Hinton

NBD: 4-fluoro-7-nitrobenz-2-oxa-1,3-diazole

NMR: nuclear magnetic resonance

OD: optical density

PC: phosphatidylcholine

PE: phosphatidylethanolamine

PG: phosphatidylglycerol

POPC: 1-palmitoyl-2-oleoyl-sn-glycero-3-phosphocholine

POPE: 1-palmitoyl-2-oleoyl-sn-glycero-3-phosphoethanolamine

POPG: 1-palmitoyl-2-oleoyl-sn-glycero-3-phospho-(1'-rac-glycerol)

RET: resonance energy transfer

r.h.: relative humidity 
The spread of multi-resistant pathogens has become an increasing threat to human health where immediate actions are needed. Bacteriocidal and fungicidal molecules are abundant in nature and promise that new pharmaceuticals can be developed by mimicking the mechanism of action of such antimicrobial compounds [1-3]. Host defense peptides are one class of antimicrobial macromolecules that have indeed served as lead compounds for the creation of more easy to prepare and/or more efficient analogues [4, 5]. Whereas in some organisms they are over-expressed when infections occur, such peptides are also stored in exposed tissues of animals and plants, where they provide an even faster and highly efficient response [1-3]. Such peptides are wide spread and currently the data bases contain over 2500 sequences from various organisms and by design [6]. A good number of peptides have been identified from frogs and other amphibians and were among the first peptides to be described for their antimicrobial activities [7,8]. These linear peptides are characterized by hydrophobic and a great number of cationic residues which confer a highly amphipathic character. When tested in biological assays they exhibit a broad spectrum of antimicrobial activities. Virucidal and tumoricidal characteristics have also been detected for magainins and other host defence peptides $[9,10]$.

When magainin peptides associate with phospholipid membranes they have been shown to adopt amphipathic $\alpha$-helical conformations with the cationic residues accumulating on one face of the helix and hydrophobic residues opposite [11-13]. When the helical domain intercalates into the membrane interface it acts like a wedge thereby destabilizing the membrane packaging [14]. As a consequence the phospholipid bilayers become leaky, the electric conductance increases and the transmembrane electrochemical gradients collapse, which ultimately results in cell killing by these and other amphipathic peptides (reviewed in e.g. $[4,15])$. The notion that membranes rather than proteinaceous receptor are the main targets of these peptides is supported by observations that enantiomers, retromers or retroenantiomers of magainins and cecropins from insects, all exhibit the high antibiotic and pore-forming activities of the parent L-peptides. [16]. Once the peptides have crossed the membrane barrier intracellular targets may also become important for some peptides (for a review see [17]). 
A number of biophysical investigations have been performed with magainins [12, 18-22], magainin analogues [23-25] and related cationic antimicrobial peptides [26,27] which revealed interesting details about their interactions with membranes. These studies revealed that the peptides preferentially intercalate into the bilayers at orientations parallel to the membrane surface in agreement with their strongly amphipathic and cationic character [4]. Notably, such biophysical data have been shown to correlate well with their activities in antibacterial assays [28], where the lipid-dependent membrane interactions of the aurein frog peptides parallels nicely their activities against bacterial species in biological assays [29]. Therefore, when insights from biophysical investigations where combined with structure-activity correlations (e.g. [30]) a number of mechanisms of action were proposed to describe pore formation in membranes either in vitro or in bacteria [4]. Such models include the formation of torrodial pores, where the peptides together with the lipid form a supramolecular assembly of high curvature [31, 32]. Furthermore the 'carpet model' was suggested, where the peptides crowd at the membrane at an alignment parallel to the surface. [15]. When a critical peptide concentration is reached the bilayer disintegrates. At lower peptide concentrations stochastic fluctuations of the peptide density along the membrane interface occur and can explain the transient and step-wise increases in membrane conductivity that have been observed experimentally [4]. Atomistic views supporting such models have also been obtained by molecular modelling calculations [33]. The various supramolecular arrangements of peptides and lipids have recently been summarized in a phase diagram that takes into account that Soft Membranes Adapt and Respond, also Transiently, to external stimuli (SMART model) [34]. Within this model one supramolecular assembly can transform into another shape and this depends on a variety of factors such as the peptide-to-lipid ratio, lipid composition, temperature. buffer composition and $\mathrm{pH}$ or other environmental factors. Within the phase diagram of the SMART model the peptides can cause lysis, formation of transient channels and under some conditions even increase the stability of lipid bilayers [14]. Having understood that peptides located at the membrane interface can exhibit strong antimicrobial activity without adopting transmembrane orientations, has resulted in the design of very 
short sequences or of peptide mimetics with considerable antibiotic action [3539].

In this paper we follow up an interesting additional observation namely the synergistic enhancements of activities of antimicrobial peptides when added in combination, which also occurs in cocktails of magainin 2 and PGLa, two peptides that are produced and stored together in the frog skin. Notably the peptides' activities are increased not only in biological assays but also when the release of fluorophores from model membranes is monitored. Indeed the addition of equimolar mixtures of these two peptides causes an increase of efficiency by almost an order of magnitude when compared to the individual components. Synergism has also been observed for other amphipathic peptides as well as for mixtures involving conventional antibiotics [13, 40-43].

So far only a few biophysical or structural investigations have been published and the molecular interactions that cause synergistic enhancements are poorly understood. Using ${ }^{15} \mathrm{~N}$ solid-state NMR spectroscopy the membrane alignment of PGLa and magainin 2 was monitored. In phosphatidylcholine membranes, where both fatty acyl are saturated, the tendency of PGLa to adopt transmembrane alignments increased in particular in the presence of magainin 2, when at the same time the latter remains surface oriented $[44,45]$. Importantly, both peptides maintain orientations parallel to the membrane surface in bilayers made of (partially) unsaturated phospholipids (e.g. POPC or POPC/POPG). Notably the latter are thought to represent more closely the natural composition of biological membranes and this result therefore seems to represent well what happens in a natural environment $[45,46]$.

Previously PGLa and magainin 2 variants were prepared with GGC extensions at either the carboxy- or the amino terminus as well as protecting groups neutralizing the charges of both termini [47]. Mixtures of these sequences were incubated in the presence and absence of PC/PG vesicles under high $\mathrm{pH}$ conditions favouring cystine bridge formation. Notably, when associated with membranes the parallel heterodimer of the two peptides preferentially formed [47]. This preformed dimer was found equally active than the mixture of wild type peptides when tested against bacteria, when at the same time the covalent linkage much 
enhanced calcein release activity from egg-PC vesicles [48]. Although such data are suggestive that specific interactions between PGLa and magainin 2 are responsible for their synergistic activities it has proven difficult to identify unique and strong interaction sites on both peptides $[41,49]$. Therefore, we further investigated the role of sequence additions that have been suspected to help in dimer formation and thereby enhance synergistic activities [47] as well as variants thereof. These sequences were tested in antimicrobial assays and the data compared with their tendency to adopt transmembrane alignments investigated. Because the in-plane to transmembrane equilibrium of PGLa is most easily shifted into its transmembrane state in thin membranes investigating ${ }^{15} \mathrm{~N}$ labelled PGLa in diC10:0-PC by ${ }^{15} \mathrm{~N}$ solid-state NMR spectroscopy provides a sensitive test for such shifts in topological equilibria. [45]. Therefore, we tested how PGLa and the modified PGLa sequences align in such thin membranes in the absence and presence of magainin 2 peptides and how their tendency to adopt more transmembrane alignment correlates with their potential to interact synergistically.

\section{MATERIALS AND METHODS}

The phospholipids (di-C10:0-PC, E. coli lipid extract) were purchased from Avanti Polar Lipids (Alabaster, AL) and used without further purification.

\section{Peptide synthesis and purification}

The peptides sequences shown in Table 1 were prepared by solid-state synthesis using a Millipore 9050 automatic peptide synthesizer and fmoc chemistry. For NMR investigations PGLa was labelled with ${ }^{15} \mathrm{~N}$ at the Ala-14 and with ${ }^{2} \mathrm{H}_{3}$ at the Ala-10 position using commercial fmoc-protected amino acids (Euriso-top, Paris, France or Isotec $®$ Sigma-Aldich St Quentin Fallavier, France).

The peptides were purified by reverse phase HPLC (Gilson, Villiers-le-Bel,

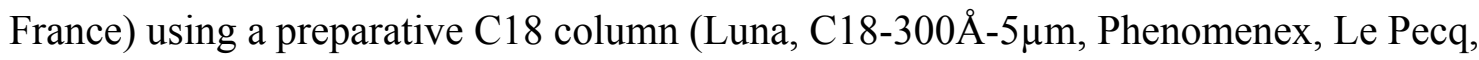
France) and an acetonitrile/water gradient. Their identity and purity (>90\%) were checked by analytical HPLC and MALDI mass spectrometry (MALDI-TOF Autoflex, Bruker Daltonics, Bremen, Germany). The purified peptide was lyophilized and stored at $-20^{\circ} \mathrm{C}$. 


\section{Table 1: Peptide sequences}

(-NH2 is indicative of an amidated, $-\mathrm{COOH}$ of a free carboxy terminus)

PGLa

PGLa (L18W)

PGLa-GGC ( L18W)

PGLa-GGS ( L18W)

PGLa-GGA ( L18W)

Magainin 2

Magainin 2- $\mathrm{COOH}$

Magainin 2-GGC

Magainin 2-GGS

Magainin 2 ( $\mathrm{Scr}, \mathrm{F} 5 \mathrm{~W})$

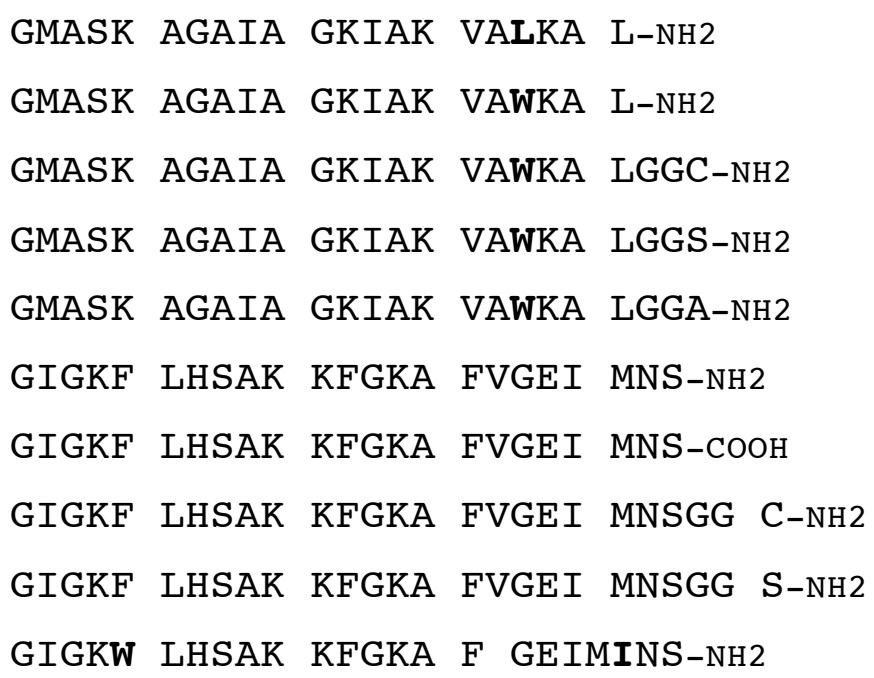

\section{Determination of antimicrobial activities}

For antimicrobial assays E. coli bacteria (ATCC25922, Ref 0335-CRM, Thermo Fisher Scientific, Courtaboeuf, France) were grown overnight on Mueller-Hinton (MH) agar plates and suspended in MH media (Fluka Analytical, Sigma Aldrich, Saint-Louis, MO, USA) to inoculate a $10 \mathrm{ml}$ preculture. The preculture was grown overnight (no longer than $18 \mathrm{~h}$ ), and used for the inoculation of test cultures (10 $\mathrm{ml}$ of $\mathrm{MH}$ ) at an $\mathrm{OD}_{550}$ of 0.2 . The test cultures were grown for $3-4 \mathrm{~h}$ at $37^{\circ} \mathrm{C}$ at 200 rpm, the turbidity was again adjusted to an $\mathrm{OD}_{550}$ of 0.2 and from this, a 1000 -fold diluted bacterial suspension was obtained corresponding to $1-2 \cdot 106 \mathrm{CFU} / \mathrm{ml}$ (colony forming units).

The antimicrobial assay was performed in 96 well microplates (F-bottom sterile non treated polystyrene, Nunc, Thermo Scientific Nunc A/S, Roskilde, Denmark). The first column is loaded with $50 \mu \mathrm{l}$ of doubly concentrated MH (2X) and completed with $50 \mu \mathrm{l}$ of an $800 \mu \mathrm{M}$ solution of peptides in $50 \%$ ethanol. Columns 2 to 11 are loaded with $50 \mu \mathrm{l}$ X MH. A two-fold dilution is successively performed from column 1 to 10 containing $50 \mu \mathrm{l}$ of $1 \mathrm{X}$ MH $1 \mathrm{X}$. Finally, the previously prepared bacterial suspension was distributed by adding $50 \mu$ lo each 
well (except column 12) resulting in $5.10^{4}$ and $1.10^{5} \mathrm{CFU} /$ well. The final peptide concentration ranges from $200 \mu \mathrm{M}$ to $0.391 \mu \mathrm{M}$ (columns 1 to 10). In each series, controls for bacterial growth (without peptides, wells of column 11), for contamination (without bacteria, column 12). Another control consisted in an additional row with the same two fold dilution than for peptides but where the ampicillin final concentration ranges from 25 to $0.0488 \mu \mathrm{M}$ (positive control for killing bacteria. Each condition was performed as triplicate within each series. Microplates are incubated at $37^{\circ} \mathrm{C}$ for $22 \mathrm{~h}$ without stirring in the incubator (Memmert INB-400, Memmert GmbH+Co.KG, Schwabach, Germany).

To monitor the bacterial growth and to determinate the $\mathrm{MIC}_{100}$ (complete inhibition of bacterial growth) of each peptide or peptide mixture, a colorimetric assay was used [50]. Reazurin when oxidized is blue, non-fluorescent and absorbs at $610 \mathrm{~nm}$. When reduced, it turns into resofurin which is pink, fluorescent and absorbs light at $610 \mathrm{~nm}$. Growing bacteria release molecules from their respiratory cycle which reduce resazurin, turning the blue bacterial suspension pink. Therefore, $20 \mu \mathrm{l}$ of resazurin at $0.2 \mathrm{mg} / \mathrm{ml}$ were added to each well and the microplates were incubated for an additional $2 \mathrm{~h}$ at $37^{\circ} \mathrm{C}$. The colour change was observed by eye, and monitored spectroscopically. To determine the MIC, the difference between $\mathrm{OD}_{570}$ and $\mathrm{OD}_{600}$ is calculated after background subtraction and averaging of triplicates.

An additional microplate regrouping the assay of different peptides was prepared and placed into the microplate reader (MultiSkan Go, Thermo Fisher Scientific, Courtaboeuf, France) with incubation at $37^{\circ} \mathrm{C}$ for $22 \mathrm{~h}$ under shaking at low speed. The $\mathrm{OD}_{600}$ was measured every $30 \mathrm{~min}$. The two methods (colorimetric and by difference of absorbance at $570 \mathrm{~nm}$ and $600 \mathrm{~nm}$ ) were compared to each other to determine the $\mathrm{MIC}_{100}$.

For most of the experiments, the commercial Mueller Hinton media has been prepared and autoclaved without further modification. When checked with a $\mathrm{pH}$ electrode, a value of 8.5 was measured in some preparations. Therefore, some experiments were repeated at a lower $\mathrm{pH}$ of 7.2 or 5.49 by adding sterile $\mathrm{HCl}$ to the autoclaved media. 


\section{Evaluation of synergistic activity}

To evaluate the synergistic activities the optical measurements were analysed in quantitative detail by first normalizing the dose response curve and then applying a sigmoidal fit of the form: $y=\frac{1}{1+\left(\frac{x}{M I C_{50}}\right)^{m}}$, where $x$ is the total peptide concentration, $\mathrm{MIC}_{50}$ is the concentration inhibiting $50 \%$ of the bacterial growth $(\mathrm{y}$ $=0.5$ at $\mathrm{MIC}_{50}$ ) and $m$ is the slope which has been fixed to 20 for this data analysis. The $\mathrm{MIC}_{50}$ determined in this manner for the peptides individually and for the peptide mixtures was then compared to the expected value in the absence of synergism with the experimental one. The expected curve for the mixture of peptide in the absence of synergism is calculated by considering the $\mathrm{MIC}_{50}$ of each peptide alone with equal contribution as they are at molar ratio 1:1 by the following equation: $y=\frac{1}{1+\left(\frac{0.5 x}{M I C_{50}^{a}}+\frac{0.5 x}{M I C_{50}^{b}}\right)^{m}}$ (with $\mathrm{x}$ being the total peptide concentration). The thus calculated expected $\mathrm{MIC}_{50}$ of the mixture was then compared to the one obtained by experiment.

The combination factor $\mathrm{CI}$ is then calculated from the $\mathrm{MIC}_{50}$ of each peptide alone and of the mixture using the following equation [51]:

$C I=\frac{0.5 \cdot M I C_{50}^{a+b}}{M I C_{50}^{a}}+\frac{0.5 \cdot M I C_{50}^{a+b}}{M I C_{50}^{b}}$. A CI value of 1 is indicative of additivity, CI $>1$ of antagonism and $\mathrm{CI}<1$ of synergism. The synergistic enhancement is obtained as $1 / \mathrm{CI}$.

\section{Sample Preparation for solid-state NMR measurements}

A homogeneous mixture of lipid and peptide in chloroform/methanol (1:1 by volume) was spread onto ultra thin cover glasses $(8 \times 22 \mathrm{~mm}$, thickness 00 , Marienfeld, Lauda-Königshofen, Germany), dried first in air and thereafter under vacuum overnight. Thereafter the membranes were equilibrated at $93 \%$ relative humidity before the glass slides were stacked on top of each other and sealed in plastic wrapping [52]. 


\section{Solid-state NMR Spectroscopy}

Proton-decoupled ${ }^{15} \mathrm{~N}$ cross-polarization (CP) spectra were acquired on a Bruker Avance wide-bore $400 \mathrm{MHz}$ NMR spectrometer equipped with a double resonance flat-coil probe [53]. An adiabatic CP pulse sequence was used [54] with a spectral width, acquisition time, CP contact time, and recycle delay of $38.5 \mathrm{kHz}, 6.7 \mathrm{~ms}, 0.8$ $\mathrm{ms}$, and $3 \mathrm{~s}$, respectively. The ${ }^{1} \mathrm{H} \pi / 2$ pulse and spinal 64 heteronuclear decoupling field strengths were $35 \mathrm{kHz}$. Typically 40000 scans were accumulated, and the spectra were zero filled to 4096 points. Typically, a $200 \mathrm{~Hz}$ exponential linebroadening was applied before Fourier transformation. Spectra were externally referenced to ${ }^{15} \mathrm{NH}_{4} \mathrm{Cl}$ at $40.0 \mathrm{ppm}$ [55].

Thereafter the baseline was corrected between $-30 \mathrm{ppm}$ and $-470 \mathrm{ppm}$. The ratio of the transmembrane signal intensity was calculated by comparing the integral from $270 \mathrm{ppm}$ to $150 \mathrm{ppm}$ with that obtained between $270 \mathrm{ppm}$ and $30 \mathrm{ppm}$.

Deuterium solid-state NMR spectra were recorded using a quadrupolar echo pulse sequence [56] with a spectral width, acquisition time, interpulse delay, and recycle delay of $500 \mathrm{kHz}, 8.2 \mathrm{~ms}, 50 \mu \mathrm{s}$, and $1.5 \mathrm{~s}$, respectively. The spectra were referenced relative to ${ }^{2} \mathrm{H}_{2} \mathrm{O}(0 \mathrm{~Hz})$. An exponential apodization function corresponding to a line broadening of $300 \mathrm{~Hz}$ was applied before Fourier transformation.

Proton-decoupled ${ }^{31} \mathrm{P}$ solid-state NMR spectra were acquired at $161.953 \mathrm{MHz}$ on a Bruker Avance widebore 400 NMR spectrometer equipped with a double resonance flat-coil probe [53]. A phase cycled Hahn-echo pulse sequence [57] with a $\pi / 2$ pulse of $2.5 \mu \mathrm{s}$, a spectral width of $75 \mathrm{kHz}$, an echo delay of $40 \mu \mathrm{s}$, and a recycle delay of $3 \mathrm{~s}$ was used. Spectra were referenced externally to $85 \% \mathrm{H}_{3} \mathrm{PO}_{4}$ at 0 ppm.

\section{RESULTS}

\section{Antimicrobial Assays}

When Magainin 2 amide and PGLa were tested for antimicrobial action against $E$. coli. $\mathrm{MIC}_{100}$ values of $25 \mu \mathrm{M}-12,5 \mu \mathrm{M}$ were obtained. When the two peptides were 
added as an equimolar mixture, the total peptide concentration needed to inhibit bacterial growth was considerably reduced in agreement with previous publications [40, 41]. Performing 2-fold dilution series, measuring the optical density or judging the redox potential in the presence of reazurin are wide-spread methods and the corresponding $\mathrm{MIC}_{100}$ values of magainin, PGLa and of a number of variants investigated here are presented in Table 2 . In order to quantitatively evaluate the synergistic enhancement of such mixture we used a more refined method where the growth curves were statistically analysed and fitted by sigmoidal transitions (Figure 1). This approach allows one to evaluate the $\mathrm{MIC}_{50}$ and its standard deviation (SD) more accurately. Notably, the $\mathrm{MIC}_{50}$ values determined here are about two to three times reduced when compared to the $\mathrm{MIC}_{100}$ obtained with the colorimetric method (Table S1).
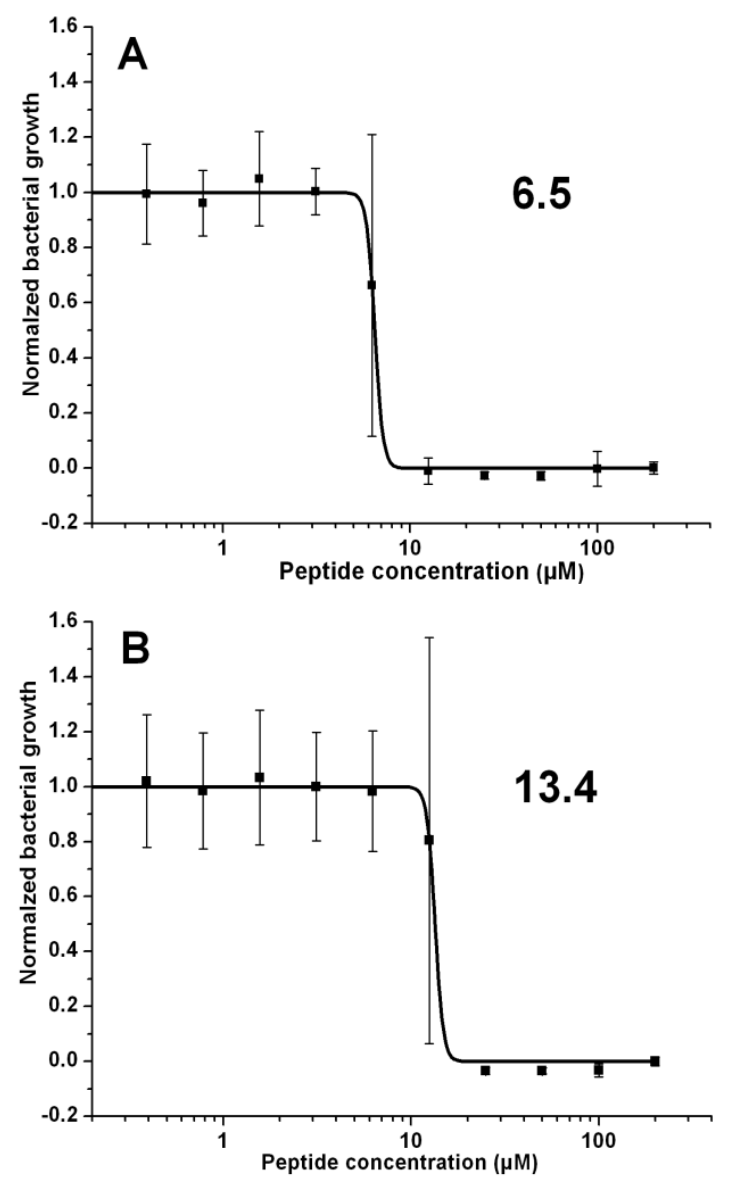

Figure 1: Normalized growth inhibition as a function of PGLa_L18W (A) and magainin 2-NH2 concentration (B). The black line is obtained by fitting the experimental data set of triplicates represented by its averages and standard deviation. The $\mathrm{MIC}_{50}$ is also indicated. 
The $\mathrm{MIC}_{50}$ values for each peptide and their mixtures were thus determined (Figure 1). In a next step the curve $\left(\mathrm{MIC}_{50}\right)$ that is expected when two peptides are mixed in the absence of synergism is calculated and compared to the experimentally measured growth inhibition (Fig. 2). From this comparison a combination factor (CI), or the synergistic enhancement is calculated.

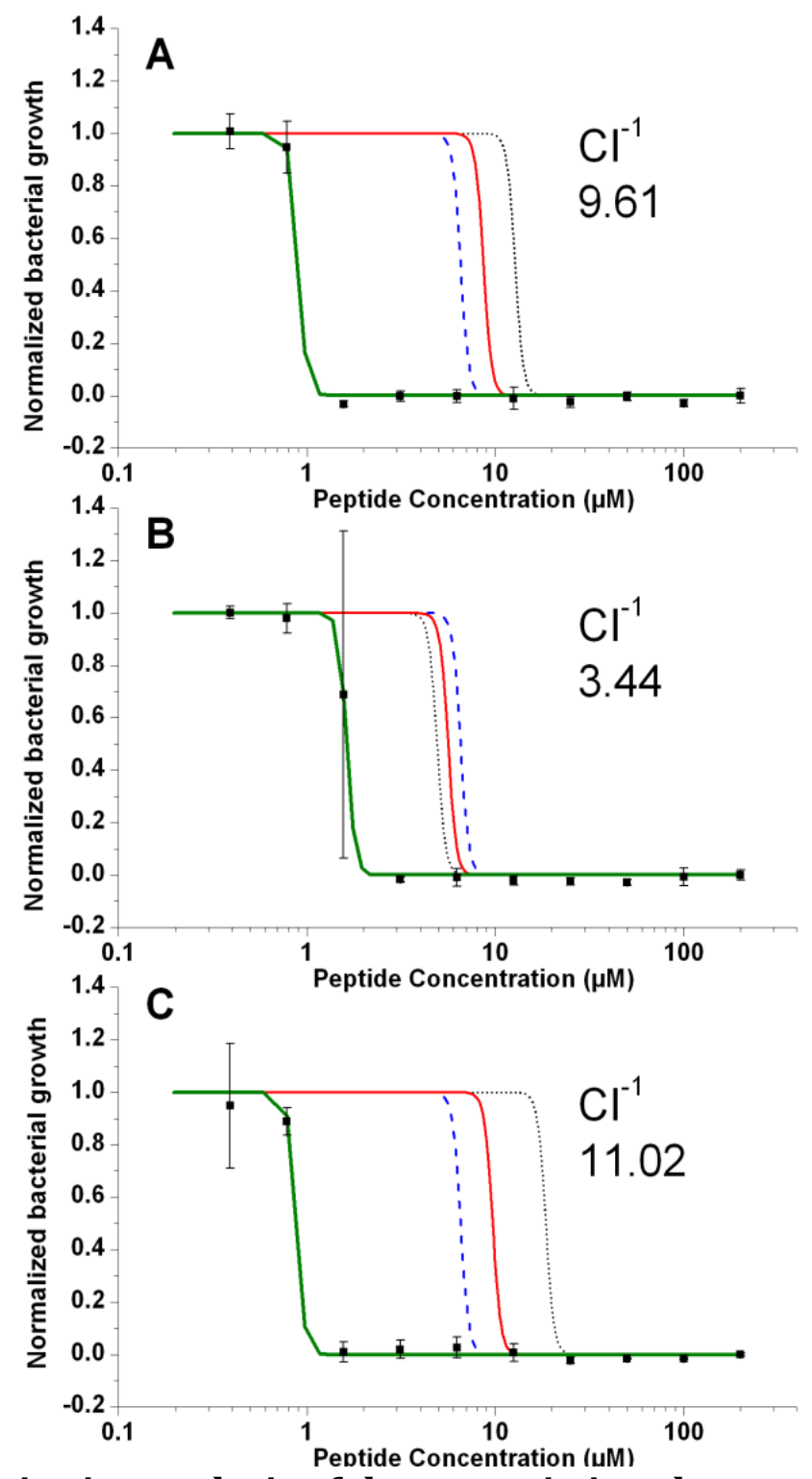

Figure 2: Quantitative analysis of the synergistic enhancements of A. PGLa L18W and magainin 2, B. PGLa L18W and magainin 2-GGC and C. PGLa L18W and magainin 2-GGS. From the normalized fits (cf. Figure 1) for PGLa (dashed line) and magainin 2-NH2 (dotted line), the expected transition curve for the corresponding mixtures of PGLa and magainin 2 peptides at molar ratio (1:1) and in absence of synergism is calculated (red line) and compared to the experimental data for the mixture (black square) and its fitted transition (green line.) 
In the past a number of peptide variants and combinations have been tested in biophysical experiments and antimicrobial assays. When the PGLa sequence was modified by replacing L18 by tryptophan, the resulting sequence was equally active in fluorescence dye release assays and synergistic activity with magainin 2 [41]. Here, we demonstrated that this variant exhibits the same antimicrobial activity as unmodified PGLa (Table S1).

Furthermore, the synergistic activities of PGLa and of magainin 2 extended by GGC at the carboxy-terminus were tested. This modification had been introduced previously to study the effect of dimerization on the biophysical characteristics of these peptides [47]. When added individually, PGLa-GGC (L18W) and magainin-GGC are both 2- to 3-times more active in the antimicrobial assays when compared to PGLa (L18W) and magainin 2 alone, respectively (Table 2). When the cysteine is replaced by serine or alanine, this improvement is reverted and MICs that are the same range or higher as those of the sequences without tripeptide extension are obtained (Table 2).

Table 2 : $\mathrm{MIC}_{50}$ (in $\mu \mathrm{M}$ ) and Synergistic Factor for mixtures of PGLa and magainin peptides. The average values and SD of $\mathrm{MIC}_{50}$ as well as the synergistic factor (1/CI, in brackets) obtained from the experimental fitting (Figures 1 and 2) are shown for the peptides alone and in mixtures. Usually, data are from 2 - 8 experiments; when no SD is shown only one experiment has been analyzed.

\begin{tabular}{|c|c|c|c|c|c|}
\hline & \multirow{3}{*}{\multicolumn{2}{|c|}{$\begin{array}{c}\text { Average } \mathrm{MIC}_{50} \\
+/-\mathrm{SD}\end{array}$}} & \multicolumn{3}{|c|}{ Magainin 2} \\
\hline & & & amide & GGC_amide & GGS_amide \\
\hline & & & $14.48 \pm 3.74$ & $5.45 \pm 0.76$ & $14.11 \pm 5.10$ \\
\hline \multirow{4}{*}{ PGLa } & L18W & $6.55+1.16$ & $\begin{array}{c}1.41 \pm 0.46 \\
\mathbf{( 7 . 6 1} \pm \mathbf{2 . 1 2})\end{array}$ & $\begin{array}{c}1.58 \pm 0.07 \\
\mathbf{( 4 . 0 4} \pm \mathbf{0 . 8 4})\end{array}$ & $\begin{array}{c}0.88 \\
\text { (11.02) }\end{array}$ \\
\hline & L18W_GGC & $2.80 \pm 1.16$ & $\begin{array}{l}1.53 \pm 0.59 \\
\mathbf{( 3 . 4 \pm 0 . 8 4 )}\end{array}$ & $\begin{array}{c}1.95 \pm 0.73 \\
\mathbf{( 2 . 3 0} \pm \mathbf{0 . 5 9 )}\end{array}$ & $\begin{array}{c}1.66 \\
(\mathbf{2} .30)\end{array}$ \\
\hline & L18W_GGS & $10.40 \pm 1.16$ & $\begin{array}{c}1.28 \pm 0.56 \\
(\mathbf{1 0 . 4 3} \pm \mathbf{3 . 9 8})\end{array}$ & $\begin{array}{c}2.35 \pm 0.06 \\
\mathbf{( 2 . 8 2} \pm \mathbf{0 . 0 7})\end{array}$ & $\begin{array}{c}1.52 \pm 0.00 \\
\mathbf{( 7 . 8 7} \pm \mathbf{2 . 5 3 )}\end{array}$ \\
\hline & L18W_GGA & $6.04 \pm 0.02$ & $\begin{array}{c}1.34 \\
(5.60)\end{array}$ & $\begin{array}{c}2.00 \pm 0.52 \\
\mathbf{( 2 . 9 6} \pm \mathbf{0 . 5 7})\end{array}$ & $\begin{array}{c}1.66 \\
\mathbf{( 4 . 6 8 )}\end{array}$ \\
\hline
\end{tabular}


In equimolar combination with magainin, with magainin-GGC or with magainin-GGS (carboxy-amidated in all cases), all of PGLa, PGLa-GGC, PGLa-GGS and PGLa-GGA (L18W in all cases) exhibit $\mathrm{MIC}_{50}$ in the 1-2 $\mu \mathrm{M}$ range (MIC $_{100}$ of 1.6$3.1 \mu \mathrm{M}$ ), which corresponds to synergistic enhancements between 2.3 and 11 (Table 2). Notably, a closely related $\mathrm{MIC}_{100}$ of $1.3 \mu \mathrm{M}$ was published for the preformed covalently heterodimer magainin-GGC/PGLa-GGC [48], where the small difference can merely represent differences in conditions between laboratories and the day-to-day reproducibility between experiments. Interestingly, a mixture of magainin-GGS and PGLa-GGS is equally active although in this case the cysteines have been replaced by serines. The synergism of this mixture when compared to the individual magainin-GGS and PGLa-GGS derivatives is about eight-fold. When compared to PGLa-GGS, the PGLa-GGA derivative exhibits a similar behaviour when tested alone or in combination with magainins suggesting that neither a cystein-mediated covalent bond nor a serine-driven hydrogen bonding interaction are required for the improved activities of the extended sequences.

When the MICs of the extended sequences are compared to each other, magainin 2 and PGLa carrying the GGC extension seem to be more efficient in antimicrobial assays than those carrying the GGA or GGS tri-peptide extensions. In some experiments the $\mathrm{pH}$ of the $\mathrm{MH}$ media turned out to range between 8 and 9 , which are conditions favourable to cystine bridge formation. Indeed, mass spectra indicate that only in the presence of the cysteines some dimers co-exist with monomers. Therefore, we also tested antimicrobial activities at lower $\mathrm{pH}$ where the chemistry is less favourable to cystine-bridge and thereby dimer formation. When the $\mathrm{pH}$ was adjusted to 7.2 or to 5.5 , the MICs of the peptides tended to decrease-when at the same time the MICs of the two GGC carrying peptides were hardly dependent on the $\mathrm{pH}$ at all. This observation suggests that at the neutral and lower $\mathrm{pH}$ the peptides become more readily available for antibacterial action, and/or that the bacteria are more sensitive to antimicrobial action. On the other hand, the formation of dimers seems to have a small or no effect on the MICs. 
Table 3 : $\mathrm{MIC}_{50}$ values (in $\mu \mathrm{M}$ ) as a function of the $\mathrm{pH}$ of the Mueller Hinton medium.

The values at $\mathrm{pH} 8.5^{*}$ are the ones obtained without adjustment of the $\mathrm{pH}$ medium. The SD are typically $\pm 1 \mu \mathrm{M}$ (cf. Table 2 ).

\begin{tabular}{|c|l|c|c|c|}
\cline { 2 - 5 } \multicolumn{2}{c|}{} & pH 8.5* & pH 7.2 & pH 5.5 \\
\hline \multirow{5}{*}{ Magainin 2 } & amide & 14.48 & 9.39 & 2.10 \\
\cline { 2 - 5 } & GGC_amide & 5.45 & 5.04 & 4.58 \\
\cline { 2 - 5 } & GGS_amide & 14.11 & 8.69 & 4.49 \\
\hline \multirow{4}{*}{ PGLa } & L18W & 6.55 & 4.49 & 4.49 \\
\cline { 2 - 5 } & L18W_GGC & 2.8 & 4.59 & 2.03 \\
\cline { 2 - 5 } & L18W_GGS & 10.4 & 9.65 & 3.91 \\
\cline { 2 - 5 } & L18W_GGA & 6.04 & 6.03 & 4.55 \\
\hline
\end{tabular}

Finally, a magainin analogue was synthesized where the deletion of valine-17 and insertion of an isoleucine at position 21 shifts the helical wheel arrangement between these residues (a helical wheel of this compound is shown in [58]). In addition F5 was replaced by tryptophan. This peptide by itself has a 4-fold increased antimicrobial activity ( $\mathrm{MIC}_{100}$ 3.1-6.3 $\mu \mathrm{M}$ ) when compared to magainin 2. When mixed with PGLa or PGLa-GGC the antimicrobial activity remains unchanged in agreement with previous single-site mutations of magainin residues F16 and E19 which cause a reduced degree of synergism [41]. However, it should be noted, that the lowest MIC $_{100}$ obtained in the experiments presented in this paper is in the $1.6 \mu \mathrm{M}$ range (Table S1). This minimal value observed in several mixtures seems independent of the MIC of the individual component as can be seen for example from the last column in Table 2 for magainin-GSS (in combination with different PGLa derivatives). As a consequence the synergistic enhancement tends to become smaller in combination with PGLa peptides that exhibit strong antimicrobial activities already as individual components. 


\section{Membrane topology of PGLa-GGX alone and in the presence of magainin 2- GGX peptides}

In previous experiments the alignment of the PGLa helix has been found to be controlled by sentive equilibria and to adopt an almost continuous range of alignments relative to the normal of PC membranes that have been prepared from saturated fatty acyl chains [45]. In particular in thin membranes the peptides exhibits an inherent tendency to adopt transmembrane tilt angles, an effect that is strongly enhanced in the presence of magainin 2 [44, 45]. Investigating the topology of PGLa peptides in di-C10:0-PC therefore provides a sensitive test for the peptides' tendency to adopt transmembrane alignments. Changes in membrane alignment can be directly monitored by ${ }^{15} \mathrm{~N}$ solid-state NMR experiments of helical peptides reconstituted into uniaxially oriented bilayers, where a ${ }^{15} \mathrm{~N}$ chemical shift in the $200 \mathrm{ppm}$ range is indicative of a transmembrane orientation of helical domains, and values $<100 \mathrm{ppm}$ correlate with alignments perpendicular to the membrane normal [59].

Previous investigations show that in di-C10:0-PC bilayers [ $\left.{ }^{15} \mathrm{~N}-\mathrm{Ala} 14\right]-\mathrm{PGLa}$ (in the absence of magainin) exhibits a maximal intensity at around $125 \mathrm{ppm}$ indicative of orientations close to the magic angle (ca. 55), which changes to 170 ppm in the presence of magainin 2 [60]. This increase in chemical shift shows that PGLa adopts a more transmembrane tilt angle in the presence of magainin 2 [45]. Here we extended these investigations by studying the PGLa L18W variant that has been used previously in studies of antimicrobial action and synergism [41]. When labelled with ${ }^{15} \mathrm{~N}$ at the alanine-14 position this mutant exhibits a chemical shift in di-C10:0-PC bilayers of $102 \pm 10$ ppm (Fig. 3A). Similar chemical shifts are observed when this sequence is extended by the GGC tripeptide ( $96 \mathrm{ppm}$ ) used in previous cross-linking studies [47] or the GGS extension (98 ppm) that we study here as an additional control (Table 2; Fig. 3B,C). Upon addition of magainin 2 the spectra of all three PGLa variants show two well defined, about equally intense resonances in the 200-210 ppm range and around 85-95 ppm (Fig. 3D-F). Thereby the spectra are indicative of a transmembrane and an in-planar population in slow exchange on the $10^{-4}$ sec time scale. In average the chemical shift increased by 25 to $50 \mathrm{ppm}$ due to the presence of magainin 2 (Fig. 3) indicating that PGLa adopts a 
more transmembrane topology. Upon addition of magainin 2-GGC the chemical shifts and topological distributions (Fig. 3 G-I) are similar than the ones obtained after addition of magainin 2 (Fig. 3D-F).
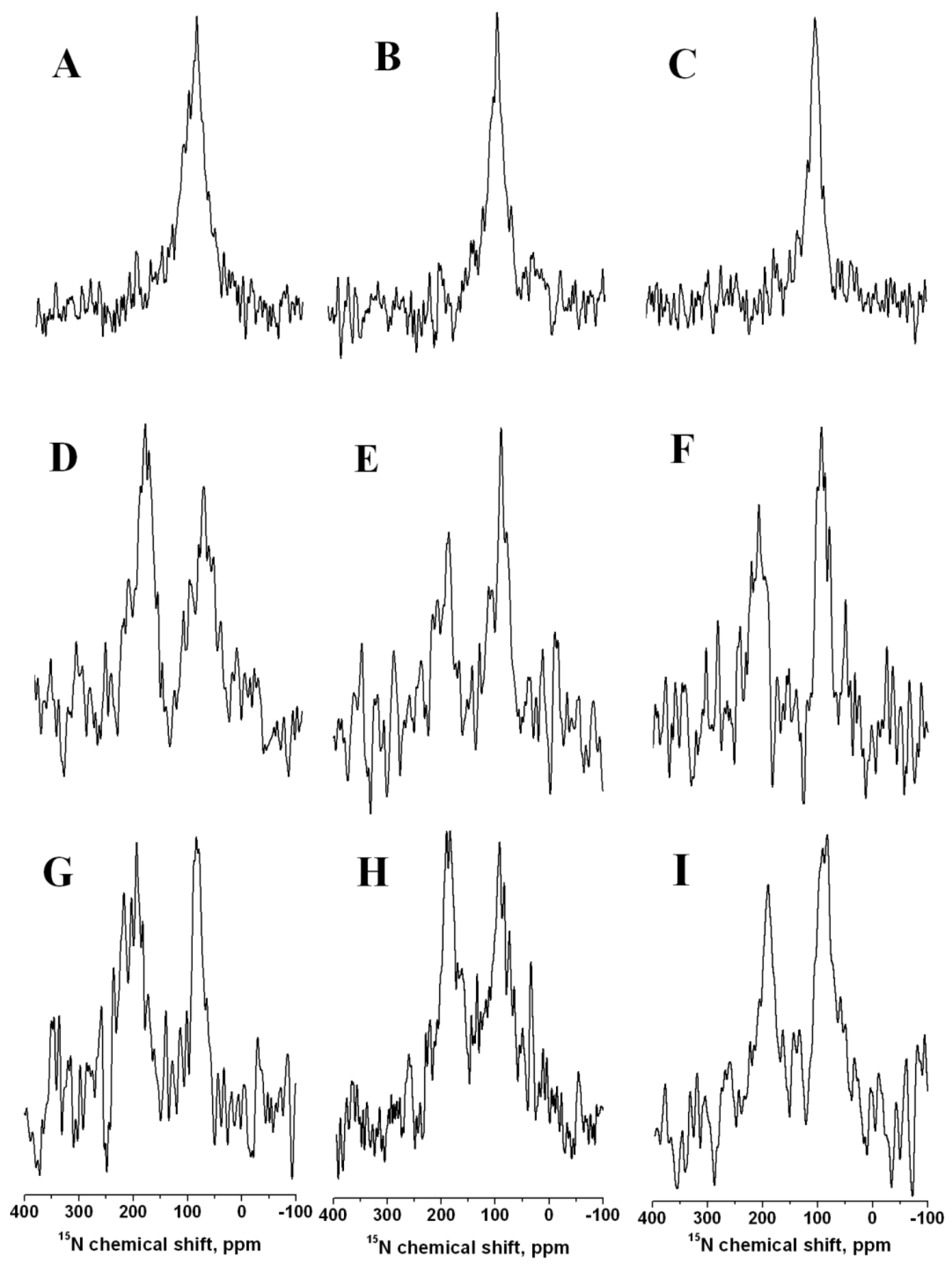

Figure 3. Proton-decoupled ${ }^{15} \mathrm{~N}$ solid-state NMR spectra of [ $\left.{ }^{15} \mathrm{~N}-\mathrm{Ala} 14\right]$-PGLa (A,D,G), [ ${ }^{15} \mathrm{~N}-A$ la14]-PGLa-GGC (B, E, H) and [15 N-Ala14]-PGLa-GGS (C,F,I) reconstituted into di-C10:0-PC bilayers oriented with the normal parallel to the magnetic field direction. Spectra were recorded in the absence $(A-C)$ of other peptides, in the presence of unlabelled magainin 2-NH2 (D-F) or magainin 2-GGC (G-I). The spectra were recorded at room temperature. 
Notably, the synergism of the mixtures shown in Figures 3D-I varies between 2.3 and 10.4 (Table 2) when at the same time the amount of transmembrane peptide remains in the range of $50 \pm 6 \%$. In order to compare the tendency of the PGLa peptides to adopt transmembrane alignments due to the presence of magainins a correlation graph was established including data from previous investigations (Fig. 4). There seems no correlation between the two experimental data.

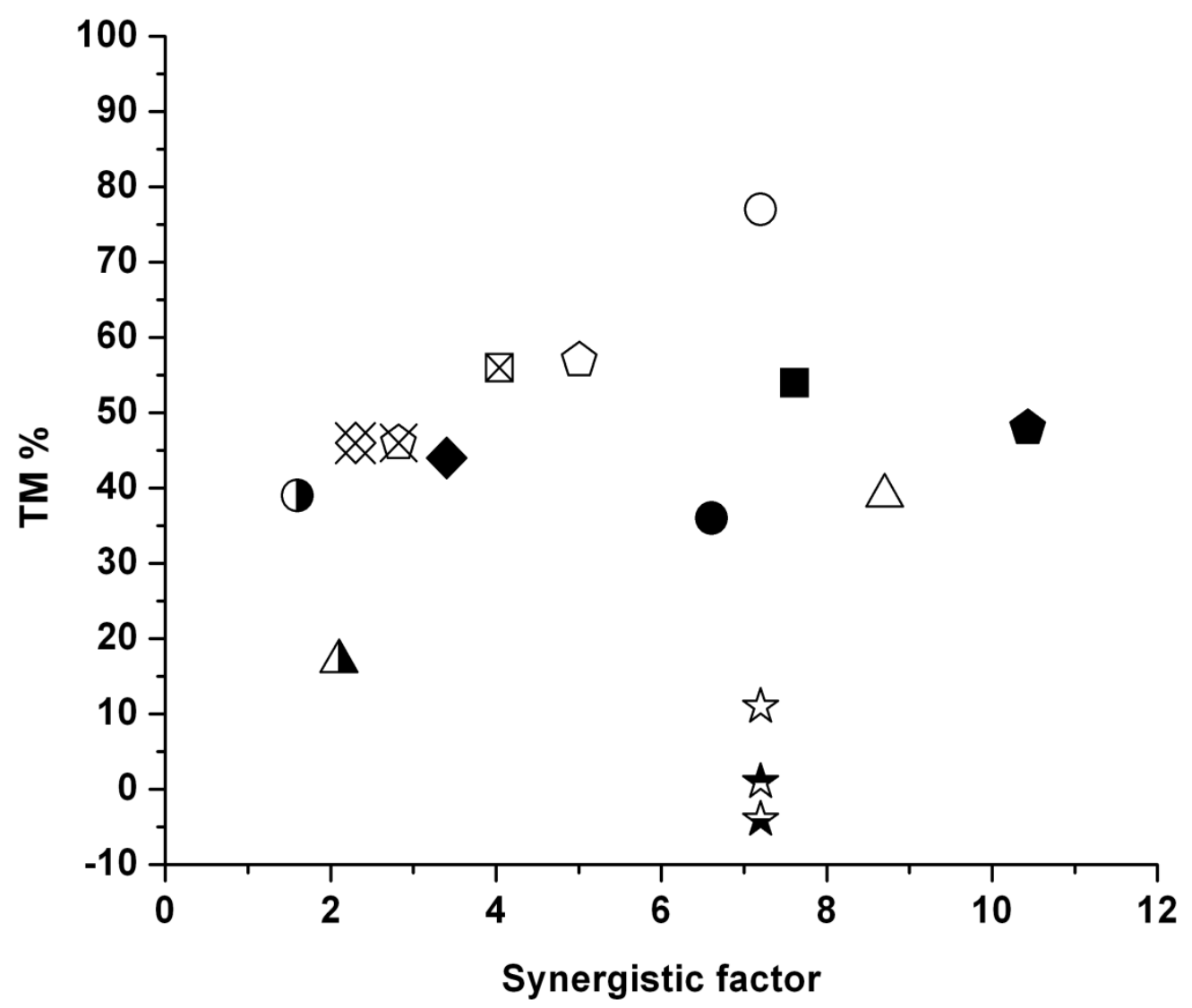

Figure 4: Correlation between the TM alignment of PGLa in the presence of magainin and the synergistic activity (Table 2). The peptides were reconstituted into oriented di-C10:0-PC (Figure 3). The symbols represent: PGLa (circle), PGLa L18W (square), PGLa L18W-GGC (diamond), PGLa-L18W-GGS (pentagone), and NBD-PGLa (triangle). Open symbols represent mixtures with magainin 2-COOH (free carboxy terminus), full when mixed with magainin 2-NH2, crossed when mixed with magainin 2-GGS and half-empty when mixed with rhodaminemagainine- $\mathrm{COOH}$. The star represents the PGLa spectrum in the presence of magainin- $\mathrm{COOH}$ when investigated by solid-state NMR in in E. coli lipid extract (open star, Fig. 5D), in the presence of POPC (black/white star) or POPC/POPG (white/black star) [45]. The fluorophore-labelled peptides were investigated in [60]. The error in determining the transmembrane ratio is typically $10 \%$. 
Therefore, we also reconstituted $\left[{ }^{2} \mathrm{H}_{3}-\mathrm{Ala} 10,{ }^{15} \mathrm{~N}\right.$-Ala14]-PGLa in supported lipid bilayers made from E. coli lipid extract and investigated the topology of its helical domain by solid-state NMR. The resulting ${ }^{15} \mathrm{~N}$ spectrum (Fig. $5 \mathrm{~A}$ ) shows a predominant peak at $87 \pm 4 \mathrm{ppm}$ from the labelled peptide bond as well as a sharp intensity at $31 \mathrm{ppm}$ which is probably from the amine of PE lipids that are frequent in bacterial membranes but carry ${ }^{15} \mathrm{~N}$ only at the low $0.4 \%$ natural abundance of this isotope. When an equimolar mixture of [15 N-Ala14]-PGLa and unlabeled magainin 2 is investigated the chemical shift of $89 \pm 4$ ppm remains identical within experimental error (Fig. 5D). The deuterium solid-state NMR spectra of the ${ }^{2} \mathrm{H}_{3}$ Ala10-site of PGLa exhibit a quadrupolar splitting of about $12 \mathrm{kHz}$ in the presence or absence of magainin 2 as well as a central intensity of natural abundance water (HDO) associated with the oriented membranes. Finally the ${ }^{31} \mathrm{P}$ solid-state NMR spectra of the phospholipids show that despite the well-oriented ${ }^{15} \mathrm{~N}$ spectra of the same sample considerable orientational dispersion of the phospholipid head groups with a chemical shift anisotropy of about $37 \mathrm{ppm}$. Although the main intensity corresponds to phospholipids that align with their long axis parallel to the sample normal (24 ppm) major intensities up to -13 ppm suggest additional topological distribution as one would observe from spherical (powder pattern) or cylindrical structures $[61,62]$. 

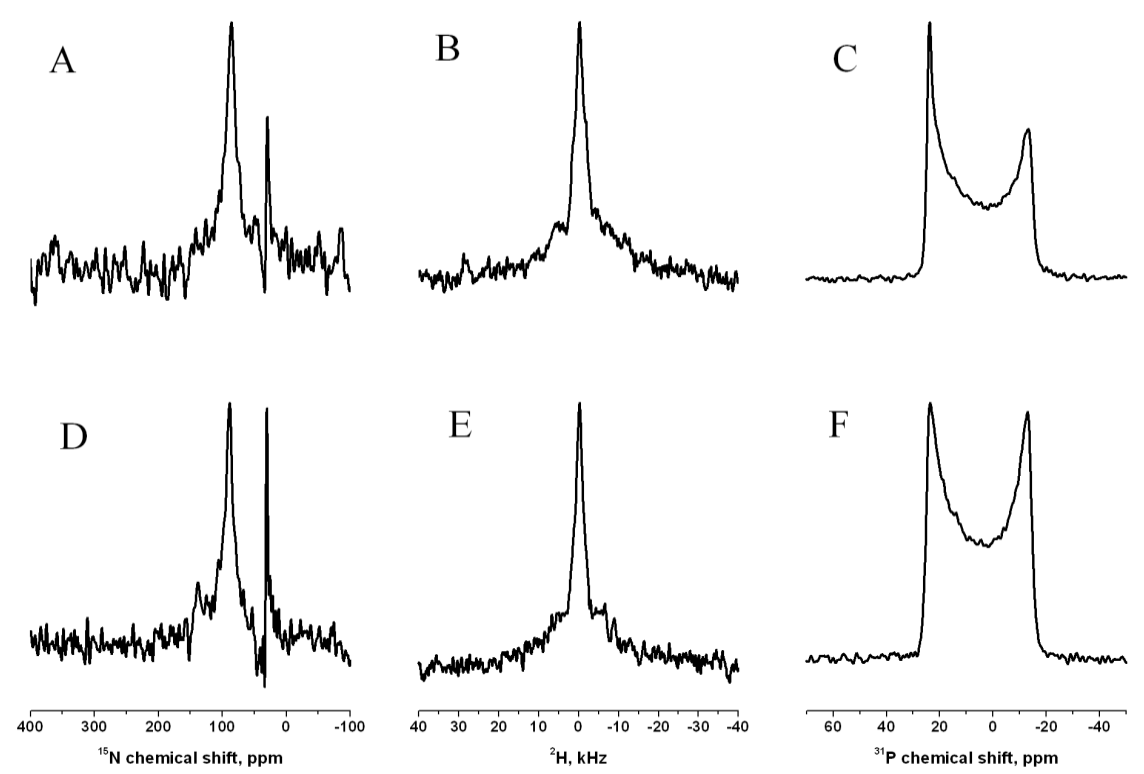

Figure 5. Proton-decoupled ${ }^{15} \mathrm{~N}(\mathrm{~A}, \mathrm{D}),{ }^{31} \mathrm{P}(\mathrm{C}, \mathrm{F})$ and ${ }^{2} \mathrm{H}(\mathrm{B}, \mathrm{E})$ spectra of $\left[{ }^{15} \mathrm{~N}\right.$ Ala14, ${ }^{2} \mathrm{H}_{3}$-Ala10]-PGLa in E.coli lipid extract membrane oriented on glass plates in the absence (A-C) and in the presence of unlabeled magainin 2-COOH. The peptide concentrations are 2 mole \% (panels A-C) and 1 mole \% of each peptide in the peptide mixture (D-F), the spectra were recorded at $310 \mathrm{~K}$.

\section{DISCUSSION}

\section{A covalent linkage does not improve synergism}

The synergistic enhancement of antimicrobial activities has been observed in mixtures involving conventional antibiotics, detergents and peptides [40, 42, 51, 63-66]. Interestingly, the peptides investigated here are produced and stored as a cocktail already in their natural environment. Although synergistic effects could potentially be useful to treat bacterial infections including multiresistance little mechanistic data are available that provide explanations on a molecular level. In cellular environments synergistic effects can sometimes be explained by one compound helping the other to access its target [66]. However, here we investigated the synergism between two antimicrobial peptides of the magainin family that are an order of magnitude more active when calcein release activities from model membranes are investigated $[41,47,48]$. The observation that a preformed heterodimer exhibits increased calcein release activity from egg-PC 
vesicles when compared to the individual peptides, albeit not in antimicrobial assays [48], seemed suggestive that close interactions between the peptides are of importance. Therefore direct interactions in the bilayer environment had been suggested initially $[41,44]$ however, these could so far not be confirmed in followup experiments $[45,49,60]$. Here, we investigate PGLa and magainin peptides with GGC extensions that have previously been designed for cross-linking studies in membranes [48]. Our experiments show that magainins with slightly modified tripeptide extensions, that are unable to form covalent cross links, exhibit less antimicrobial but even higher synergistic activities, demonstrating that the covalent bond is not a requirement for enhancement (Table 2).

\section{Sequence alterations that affect synergism}

When calcein release has been studied in the presence of mixtures of PGLa and magainin 2 the dye efflux is most pronounced when equimolar mixtures of the peptides were applied [41]. Interestingly the peptides have to fulfil specific requirements and synergism is only observed for some cocktails of antibiotics [63], detergent [64] or peptides $[40,65]$, as well as combinations of peptides with other compounds $[42,64$, 66] but not for any combination of sequences. Here we show that synergisms remains active when the L18 position of PGLa is replaced by tryptophan (Table S1). In contrast the charge of the E19 site seems important as glutamine or lysine replacements affect the synergistic interaction with magainin $2[41,49]$. Furthermore, it was possible to modify either the amino [60] or the carboxy terminus of the peptides (Tables 2 and 3) without abolishing synergistic interactions. Therefore, although the peptide interactions are somehow linked to the peptide sequences, they are not specific like receptor-ligand interactions. In contrary their presence has been difficult too proof in solid-state NMR [49] and fluorescence spectroscopy investigations [60], although the large size of the fluorophores used in the latter approach may influence the peptide-membrane and peptide-peptide interactions. Notably effects on synergism are obtained for both amino- (decrease; [60]) and carboxy-terminal modifications (increase; Table 2) suggesting that the peptide as a whole rather than a few specific interaction sites are involved. 


\section{How does the membrane topology of PGLa relate to synergism?}

Because in phosphatidylcholine membranes made of saturated fatty acyl chains PGLa was shown to adopt transmembrane alignments in the presence of magainin $2[44,45]$ pore formation by hererologous transmembrane helical bundle has been suggested to explain synergistic enhancements [44]. However, in bilayers representing more closely the natural composition of biological membranes both peptides remain in a stable alignment parallel to the surface $[45,46]$. In this context it should be noted that testing the alignment of ${ }^{15} \mathrm{~N}-\mathrm{PGLa}$ in di-C10:0-PC is quite sensitive to even small changes in the peptide sequence. For example, whereas the native PGLa exhibits a chemical shift of $125 \mathrm{ppm}$ this value shifts to $100 \mathrm{ppm}$ (Fig. 3A) for the L18W mutation, corresponding to a change in tilt angle of $12^{\circ}$ or of the pitch angle by $150^{\circ}$, or a combination thereof. In contrast the $\leq 10 \mathrm{ppm}$ difference observed upon extending with the tripeptide GGX (Fig. 3B,C) reflects a comparatively small effect at the alanine-14 site.

Upon addition of magainins, the broad peak intensities of PGLa (L18W) peptides, with or without the tripeptide extensions, split into two well-resolved peak intensities were the chemical shift values are indicative that about half the helices insert into the membrane and the remaining fraction a more surface-oriented alignment (Figs. 3D-I). In average a more inserted configuration is obtained for all of the peptide combinations investigated here (Fig. 3D-H). This contrasts the addition of NBD fluorophores to the amino-terminus of PGLa which resulted in a more in-plane alignment. Notably, the addition of NBD to PGLa as well as of magainins to the NBD-PGLa resulted in a broadened topological distribution as revealed by the ${ }^{15} \mathrm{~N}$ intensities [60].

Although these measurements are of interest for our understanding what makes a peptide like PGLa respond to small modifications of the membrane or the presence of magainin 2 [45] there seems no correlation between these topological changes observed in di-saturated PC or PC/PG membranes $[45,46]$ and the synergistic enhancement of antibacterial activity (Figure 4). In contrary, solid-state NMR investigations on model membranes of more natural composition such as POPC, POPC/POPG [45, 46] or E. coli lipid extracts (Fig. 5) reveal that both peptides adopt stable alignments parallel to the membrane surface also when added in conjunction. Notably, the ${ }^{15} \mathrm{~N}$ chemical shift of $\left[{ }^{15} \mathrm{~N}-\mathrm{Ala} 14\right]-\mathrm{PGLa}$ is within experimental error identical in all three membranes and 
does not change significantly when magainin 2 is added at equimolar amounts (Fig. 5A,B,D,E) $[45,46]$. In contrast, when ${ }^{2} \mathrm{H}$ solid-state NMR measurements of $\left[{ }^{2} \mathrm{H}_{3}\right.$ Ala10]-PGLa are compared from the E.coli lipid bilayers (Fig. 5B,E) or DMPC or DMPC/DMPG [44, 67] the different quadrupolar splittings (12 kHz and $30 \mathrm{kHz})$ reflect the different topologies in these bilayers, suggesting again that conclusions about the antimicrobial action and synergistic interactions of antimicrobial peptides should be considered with care when measured in saturated membranes.

\section{Alternative models for synergistic interactions}

Together, these data are suggestive that alternative models explaining synergistic interactions in membrane have to be found. Interestingly, the presence of $2 \mathrm{~mole} \%$ PGLa causes considerable orientational heterogeneity at the level of the phospholipid head groups. The ${ }^{31} \mathrm{P}$ NMR spectra of supported E.coli lipid membranes at $310 \mathrm{~K}$ cover an anisotropy of about 37 ppm (Fig. 5C) which compares well to the PE and PG tensors under these conditions $[68,69]$. Whereas the intensity at 24 ppm correlates with phospholipids with their long axis parallel to the sample normal, i.e. they are wellaligned relative to the surfaces of the glass support [70], the intensities at lower chemical shift reveal considerable orientational dispersion. This could arise from the conformational details at the level of the lipid head group, as observed upon changes in the electric surface charge [71], or from the lipid molecule as a whole. In the latter case major supramolecular rearrangements may be involved such as the loss of orientational order of the sample [72], the formation of cylindrical tubes of large diameter [61], membrane thinning and/or high local curvature [73]. Notably the intensities between 20 ppm and -15 ppm considerably increase when 1 mole\% each of PGLa and magainin 2 have been reconstituted (Fig. $5 \mathrm{~F}$ ) and it is tempting to speculate that the synergism that comes with such mixtures relates to such changes in the lipid macroscopic arrangements and phase properties [45].

A view emerges in which synergism occurs for example by lipid-mediated rather than strong direct interactions between the peptides. Here we used and refined sequences that have been developed early to cross-link PGLa and magainin peptides [47]. These studies indicated that the peptides preferentially cross-link when carrying cysteines that favour a relative alignment of the peptides parallel to 
each other. The unsaturated fatty acyl composition of the egg yolk PC / egg yolk PG membranes used in these studies is suggestive or an alignment of the peptides parallel to the bilayer surface $[45,47]$. The high peptide density that usually occurs during these experiments is suited to reveal relative interaction preferences rather than indications of absolute interaction strength (e.g. [74]). Furthermore the positive charge of the amino-terminus of PGLa-GGC and magainin-GCC prepared for the cross-linking investigations was neutralized by acetylation $[48,75]$, which probably improves the interactions between these globally cationic peptides. Accordingly, RET [60], ITC (A. Marquette \& B. Bechinger, unpublished) and solidstate NMR measurements [49] agree that the interaction between the two sequences are weak.

Such interactions could for example be electrostatic and/or mediated by the lipids $[45,60]$. The important role of the magainin 2 E19 site suggests that electrostatic interactions indeed play an important role [41]. Although overall cationic the charge distribution along the peptide structures is asymmetric and therefore a dipolar moment is created when the peptide interacts with the membrane in its helical conformation [60] favouring certain relative helix orientations over others $[75,76]$. Notably, we have recently observed mesophaselike arrangements with head-to-head/tail-to-tail molecular dipoles of an in-plane oriented cationic amphipathic peptide by fluorescence quenching spectroscopy [77] and similar interactions could occur in magainin / PGLa mixtures.

In summary, the results presented in this paper do not reveal a correlation between the peptides' tendency to adopt transmembrane alignments. In contrast experiments with E.coli lipid extracts suggest that synergy occurs when both PGLa and magainin remain aligned parallel to the membrane surface. Furthermore, the possibility to form covalent heterodimers does not improve the capacity of PGLa / magainin mixtures to interact in a synergistic manner. Therefore, we suggest that more indirect interactions, possibly through the lipid phase are responsible and that modulations of the lipid packing may play an important role for synergistic interactions. 


\section{ACKNOWLEDGEMENTS}

We are grateful Delphine Hatey for help during peptide synthesis and purification.

We are thankful for the financial support by of the Agence Nationale de la

Recherche (projects TRANSPEP 07-PCV-0018, ProLipIn 10-BLAN-731, membraneDNP 12-BSV5-0012, MemPepSyn 14-CE34-0001-01 and the LabEx Chemistry of Complex Systems 10-LABX-0026_CSC), the University of Strasbourg, the CNRS, the Région Alsace and the RTRA International Center of Frontier Research in Chemistry.

\section{REFERENCES}

[1] M. Zasloff. Antimicrobial peptides in health and disease. N Engl J Med (2002);347:1199-200.

[2] H. G. Boman. Antibacterial peptides: basic facts and emerging concepts. J Intern Med (2003);254:197-215.

[3] F. Garcia-Olmedo, A. Molina, J. M. Alamillo, P. Rodriguez-Palenzuela. Plant defense peptides. Biopolymers (1999);47:479-91.

[4] B. Bechinger. The structure, dynamics and orientation of antimicrobial peptides in membranes by multidimensional solid-state NMR spectroscopy. Biochimica et Biophysica Acta (1999);1462:157-83.

[5] P. M. Hwang, H. J. Vogel. Structure-function relationships of antimicrobial peptides. BiochemCell Biol (1998);76:235-46.

[6] G. Wang, X. Li, Z. Wang. APD2: the updated antimicrobial peptide database and its application in peptide design. Nucleic Acids Res (2009);37:D933-D7.

[7] G. Kiss, H. Michl. öber das Giftsekret der Gelbbauchunke Bombina variegata L Toxicon (Oxford) (1962);1:33-9.

[8] M. Zasloff. Magainins, a class of antimicrobial peptides from Xenopus skin: Isolation, characterization of two active forms, and partial cDNA sequence of a precursor. ProcNatlAcadSciUSA (1987);84:5449-53.

[9] R. A. Cruciani, J. L. Barker, M. Zasloff, H. C. Chen, O. Colamonici. Antibiotic magainins exert cytolytic activity transformed cell lines through channel formation. Proceedings of the National Academy of Sciences USA (1991);88:37926.

[10] H. M. Chen, W. Wang, D. Smith, S. C. Chan. Effects of the anti-bacterial peptide cecropin B and its analogs, cecropins B1 and B2, on liposomes, bacteria and cancer cells. Biochimica et Biophysica Acta - General Subjects (1997);1336:171-9.

[11] J. Gesell, M. Zasloff, S. J. Opella. Two-dimensional 1 H NMR experiments show that the 23-residue magainin antibiotic peptide is an a-helix in dodecylphosphocholine micelles, sodium dodecylsulfate micelles, and trifluoroethanol/water solution. JBiomolNMR (1997);9:127-35. 
[12] B. Bechinger, M. Zasloff, S. J. Opella. Structure and Dynamics of the Antibiotic Peptide PGLa in Membranes by Multidimensional Solution and SolidState NMR Spectroscopy. BiophysJ (1998);74:981-7.

[13] E. F. Haney, H. N. Hunter, K. Matsuzaki, H. J. Vogel. Solution NMR studies of amphibian antimicrobial peptides: linking structure to function? Biochim Biophys Acta (2009);1788:1639-55.

[14] B. Bechinger. Rationalizing the membrane interactions of cationic amphipathic antimicrobial peptides by their molecular shape. Cur Opin Colloid Interface Scie, Surfactants (2009);14:349-55

[15] Y. Shai. Mechanism of the binding, insertion, and destabilization of phospholipid bilayer membranes by alpha-helical antimicrobial and cell nonselective lytic peptides. Biochimica et Biophysica Acta (1999);1462:55-70.

[16] D. Wade, A. Boman, B. Wahlin, C. M. Drain, D. Andreu, H. G. Boman, et al. All$D$ amino acid-containing channel-forming antibiotic peptides. ProcNatlAcadSciUSA (1990);87:4761-5.

[17] K. A. Brogden. Antimicrobial peptides: pore formers or metabolic inhibitors in bacteria? NatRevMicrobiol (2005);3:238-50.

[18] B. Bechinger, M. Zasloff, S. J. Opella. Structure and Interactions of Magainin Antibiotic Peptides in Lipid Bilayers: A Solid-State NMR Investigation. BiophysJ (1992);62:12-4.

[19] B. Bechinger, M. Zasloff, S. J. Opella. Structure and orientation of the antibiotic peptide magainin in membranes by solid-state NMR spectroscopy. Protein Sci (1993);2:2077-84.

[20] Y. Pouny, D. Rapaport, A. Mor, P. Nicolas, Y. Shai. Interaction of antimicrobial dermaseptin and its fluorescently labeled analogues with phospholipid membranes. Biochemistry-Us (1992);31:12416-23.

[21] K. Matsuzaki, O. Murase, H. Tokuda, S. Funakoshi, N. Fujii, K. Miyajima. Orientational and Aggregational States of Magainin 2 in Phospholipid Bilayers. Biochemistry-Us (1994);33:3342-9.

[22] P. Tremouilhac, E. Strandberg, P. Wadhwani, A. S. Ulrich. Conditions affecting the re-alignment of the antimicrobial peptide PGLa in membranes as monitored by solid state 2H-NMR. Biochim Biophys Acta (2006);1758:1330-42.

[23] A. Ramamoorthy, S. Thennarasu, D. K. Lee, A. Tan, L. Maloy. Solid-state NMR investigation of the membrane-disrupting mechanism of antimicrobial peptides MSI-78 and MSI-594 derived from magainin 2 and melittin. Biophys] (2006);91:206-16.

[24] E. Strandberg, N. Kanithasen, D. Tiltak, J. Burck, P. Wadhwani, O.

Zwernemann, et al. Solid-state NMR analysis comparing the designer-made antibiotic MSI-103 with its parent peptide PGLa in lipid bilayers. Biochemistry-Us (2008);47:2601-16.

[25] A. J. Mason, W. Moussaoui, T. Abdelrhaman, A. Boukhari, P. Bertani, A. Marquette, et al. Structural determinants of antimicrobial and antiplasmodial activity and selectivity in histidine rich amphipathic cationic peptides. J Biol Chem (2009);284:119-33.

[26] J. M. Resende, C. M. Moraes, V. H. D. O. Munhoz, C. Aisenbrey, R. M. Verly, P. Bertani, et al. Membrane structure and conformational changes of the antibiotic 
heterodimeric peptide distinctin by solid-state NMR spectroscopy. ProcNatlAcadSciUSA (2009);106:16639-44.

[27] J. M. Resende, R. M. Verly, C. Aisenbrey, C. Amary, P. Bertani, D. Pilo-Veloso, et al. Membrane interactions of Phylloseptin-1, -2 , and -3 peptides by oriented solid-state NMR spectroscopy. Biophys J (2014);107:901-11

[28] D. Roversi, V. Luca, S. Aureli, Y. Park, M. L. Mangoni, L. Stella. How Many AMP Molecules Kill a Bacterium? Spectroscopic Determination of PMAP-23 Binding to E. Coli. Biophys J (2014);106:292A-A.

[29] J. T. J. Cheng, J. D. Hale, M. Elliott, R. E. W. Hancock, S. K. Straus. The importance of bacterial membrane composition in the structure and function of aurein 2.2 and selected variants. Biochim Biophys Acta (2011);1808:622-33.

[30] T. C. B. Vogt, B. Bechinger. The interactions of histidine-containing amphipathic helical peptide antibiotics with lipid bilayers: The effects of charges and pH. J Biol Chem (1999);274:29115-21.

[31] S. J. Ludtke, K. He, W. T. Heller, T. A. Harroun, L. Yang, H. W. Huang. Membrane pores induced by magainin. Biochemistry-Us (1996);35:13723-8.

[32] K. Matsuzaki. Magainins as paradigm for the mode of action of pore forming polypeptides. Biochimica et Biophysica Acta (1998);1376:391-400.

[33] H. Leontiadou, A. E. Mark, S. J. Marrink. Antimicrobial peptides in action. J AmChemSoc (2006);128:12156-61.

[34] B. Bechinger. The SMART model: Soft Membranes Adapt and Respond, also Transiently, to external stimuli. J Peptide Sci (2015, in press).

[35] A. Makovitzki, J. Baram, Y. Shai. Antimicrobial lipopolypeptides composed of palmitoyl Di- and tricationic peptides: in vitro and in vivo activities, self-assembly to nanostructures, and a plausible mode of action. Biochemistry-Us (2008);47:10630-6.

[36] J. A. Patch, A. E. Barron. Helical peptoid mimics of magainin-2 amide. J AmChemSoc (2003);125:12092-3.

[37] E. A. Porter, B. Weisblum, S. H. Gellman. Mimicry of host-defense peptides by unnatural oligomers: antimicrobial beta-peptides. J Am Chem Soc (2002);124:7324-30.

[38] K. Kuroda, W. F. DeGrado. Amphiphilic polymethacrylate derivatives as antimicrobial agents. J Am Chem Soc (2005);127:4128-9.

[39] A. Violette, S. Fournel, K. Lamour, O. Chaloin, B. Frisch, J. P. Briand, et al. Mimicking helical antibacterial peptides with nonpeptidic folding oligomers. Chem Biol (2006);13:531-8.

[40] H. V. Westerhoff, M. Zasloff, J. L. Rosner, R. W. Hendler, A. de Waal, G. Vaz, et al. Functional synergism of the magainins PGLa and magainin-2 in Escherichia coli, tumor cells and liposomes. European Journal of Biochemistry (1995);228:257-64. [41] K. Matsuzaki, Y. Mitani, K. Akada, O. Murase, S. Yoneyama, M. Zasloff, et al. Mechanism of synergism between antimicrobial peptides magainin 2 and PGLa. Biochemistry-Us (1998);37:15144-53.

[42] C. L. Bashford, G. M. Alder, G. Menestrina, K. J. Micklem, J. J. Murphy, J. A. Pasternack. Membrane damage by hemolytic viruses,toxins,complement,and other cytotoxic agents. J Biol Chem (1986);261:9300-8. 
[43] S. P. Liu, L. Zhou, R. Lakshminarayanan, R. W. Beuerman. Multivalent Antimicrobial Peptides as Therapeutics: Design Principles and Structural Diversities. Int J Pept Res Ther (2010);16:199-213.

[44] P. Tremouilhac, E. Strandberg, P. Wadhwani, A. S. Ulrich. Synergistic transmembrane alignment of the antimicrobial heterodimer PGLa/magainin. J Biol Chem (2006);281:32089-94.

[45] E. Salnikov, B. Bechinger. Lipid-controlled peptide topology and interactions in bilayers: structural insights into the synergistic enhancement of the antimicrobial activities of PGLa and magainin 2. . Biophysical J (2011);100:147380 .

[46] E. Strandberg, J. Zerweck, P. Wadhwani, A. S. Ulrich. Synergistic Insertion of Antimicrobial Magainin-Family Peptides in Membranes Depends on the Lipid Spontaneous Curvature. Biophys J (2013);104:L09-L11.

[47] T. Hara, Y. Mitani, K. Tanaka, N. Uematsu, A. Takakura, T. Tachi, et al. Heterodimer formation between the antimicrobial peptides magainin 2 and PGLa in lipid bilayers: a cross-linking study. Biochemistry-Us (2001);40:12395-9. [48] M. Nishida, Y. Imura, M. Yamamoto, S. Kobayashi, Y. Yano, K. Matsuzaki. Interaction of a magainin-PGLa hybrid peptide with membranes: insight into the mechanism of synergism. Biochemistry-Us (2007);46:14284-90.

[49] J. Zerweck, E. Strandberg, P. Wadhwani, A. S. Ulrich. Structure Activity Relationship for a Synergistic Pair of Antimicrobial Peptides from the Magainin Family. Biophys J (2014);106:294a.

[50] D. Amsterdam. Susceptibility testing of antimicrobials in liquid media. In: Antibiotics in laboratory medicine. In: Loman V, editor. 4th ed: Williams and Wilkins,Baltimore, MD; 1996, p. 52-111.

[51] T. C. Chou. Theoretical Basis, Experimental Design, and Computerized Simulation of Synergism and Antagonism in Drug Combination Studies. Pharmacol Rev (2006);58:621-81.

[52] C. Aisenbrey, P. Bertani, B. Bechinger. Solid-state NMR investigations of membrane-associated antimicrobial peptides. In: Guiliani A, Rinaldi AC, editors. Antimicrobial Peptides N.Y.: Humana Press, Springer; 2010, p. 209-33.

[53] B. Bechinger, S. J. Opella. Flat-Coil Probe for NMR Spectroscopy of Oriented Membrane Samples. JMagnReson (1991);95:585-8.

[54] S. Hediger, B. H. Meier, R. R. Ernst. Adiabatic passage Hartmann-Hahn cross polarization in NMR under magic angle sample spinning. ChemPhysLett (1995);240:449-56.

[55] P. Bertani, J. Raya, B. Bechinger. $15 \mathrm{~N}$ chemical shift referencing in solid state NMR. (2014, submitted).

[56] J. H. Davis, K. R. Jeffrey, M. Bloom, M. I. Valic, T. P. Higgs. Quadrupolar Echo Deuteron Magnetic Resonance Spectroscopy in Ordered Hydrocarbon Chains. ChemPhysLett (1976);42:390-4.

[57] M. Rance, R. A. Byrd. Obtaining High-Fidelity Spin-1/2 Powder Spectra in Anisotropic Media: Phase-Cycled Hahn Echo Spectroscopy. Journal of Magnetic Resonance (1983);52:221-40.

[58] P. Kemayo Koumkoua, C. Aisenbrey, E. S. Salnikov, O. Rifi, B. Bechinger. On the design of supramolecular assemblies made of peptides and lipid bilayers. J Peptide Scie (in press) (2014). 
[59] B. Bechinger, C. Sizun. Alignment and structural analysis of membrane polypeptides by 15N and 31P solid-state NMR spectroscopy Concepts in Magnetic Resonance (2003);18A:130 -45

[60] A. Marquette, E. Salnikov, E. Glattard, C. Aisenbrey, B. Bechinger. Magainin 2-PGLa interactions in membranes - two peptides that exhibit synergistic enhancement of antimicrobial activity. Curr Top Med Chem (2015, submitted).

[61] J. J. Buffy, M. J. McCormick, S. Wi, A. Waring, R. I. Lehrer, M. Hong. Solid-state NMR investigation of the selective perturbation of lipid bilayers by the cyclic antimicrobial peptide RTD-1. Biochemistry-Us (2004);43:9800-12.

[62] C. Aisenbrey, U. S. Sudheendra, H. Ridley, P. Bertani, A. Marquette, S. Nedelkina, et al. Helix orientations in membrane-associated Bcl-X L determined by 15 N solid-state NMR spectroscopy. EurBiophys] (2007);36:451-60.

[63] J. F. Acar. Antibiotic synergy and antagonism. Med Clin North Am (2000);84:1391-406.

[64] H. Patel, Q. Huynh, D. Barlehner, H. Heerklotz. 1+1=3? Concerted Action of Membrane Permeabilizers. Biophys J (2014);106:293A-A.

[65] S. Kobayashi, Y. Hirakura, K. Matsuzaki. Bacteria-selective synergism between the antimicrobial peptides alpha-helical magainin 2 and cyclic beta-sheet tachyplesin I: toward cocktail therapy. Biochemistry-Us (2001);40:14330-5.

[66] R. P. Darveau, M. D. Cunningham, C. L. Seachord, L. Cassianoclough, W. L. Cosand, J. Blake, et al. Beta-Lactam Antibiotics Potentiate Magainin-2 Antimicrobial Activity Invitro and Invivo. Antimicrob Agents Ch (1991);35:1153-9.

[67] E. Strandberg, P. Tremouilhac, P. Wadhwani, A. S. Ulrich. Synergistic transmembrane insertion of the heterodimeric PGLa/magainin 2 complex studied by solid-state NMR. Biochim Biophys Acta (2009);1788:1667-79.

[68] M. F. Brown, J. Seelig. Influence of cholesterol on the polar region of phosphatidylcholine and phosphatidylethanolamine bilayers. Biochemistry-Us (1978);17:381-4.

[69] P. J. Sherman, R. J. Jackway, J. D. Gehman, S. Praporski, G. A. McCubbin, A. Mechler, et al. Solution Structure and Membrane Interactions of the Antimicrobial Peptide Fallaxidin 4.1a: An NMR and QCM Study. Biochemistry-Us (2009);48:11892-901.

[70] B. Bechinger, E. S. Salnikov. The membrane interactions of antimicrobial peptides revealed by solid-state NMR spectroscopy. Chem Phys Lipids (2012);165:282-301.

[71] J. Seelig, P. M. Macdonald, P. G. Scherer. Phospholipid Head Groups as Sensors of Electric Charge in Membranes. Biochemistry-Us (1987);26:7535-41.

[72] B. Bechinger, R. Kinder, M. Helmle, T. B. Vogt, U. Harzer, S. Schinzel. Peptide structural analysis by solid-state NMR spectroscopy. Biopolymers (1999);51:17490.

[73] C. Kim, J. Spano, E. K. Park, S. Wi. Evidence of pores and thinned lipid bilayers induced in oriented lipid membranes interacting with the antimicrobial peptides, magainin-2 and aurein-3.3. Biochim Biophys Acta (2009);1788:1482-96. [74] M. Schumann, M. Dathe, T. Wieprecht, M. Beyermann, M. Bienert. The tendency of magainin to assosciate upon binding to phospholipid bilayers. Biochemistry-Us (1997);36:4345-51. 
[75] T. Hara, H. Kodama, M. Kondo, K. Wakamatsu, A. Takeda, T. Tachi, et al. Effects of peptide dimerization on pore formation: Antiparallel disulfide-dimerized magainin 2 analogue. Biopolymers (2001);58:437-46.

[76] E. Han, H. Lee. Synergistic effects of magainin 2 and PGLa on their heterodimer formation, aggregation, and insertion into the bilayer. Rsc Adv (2015);5:2047-55.

[77] C. Aisenbrey, B. Bechinger. Molecular Packing of Amphipathic Peptides on the Surface of Lipid Membranes. Langmuir (2014);30:10374-83. 
SUPPLEMETARY INFORMATION

\section{Investigations of the synergistic enhancement of antimicrobial activity in mixtures of magainin 2 and PGLa}

Elise Glattard\#, Evgeniy S. Salnikov\#, Christopher Aisenbrey and Burkhard Bechinger*

Table S1: The antimicrobial activities $\left(\mathrm{MIC}_{100}\right.$ in $\left.\mu \mathrm{M}\right)$ of magainin 2 and PGLa, derivatives and combinations thereof.

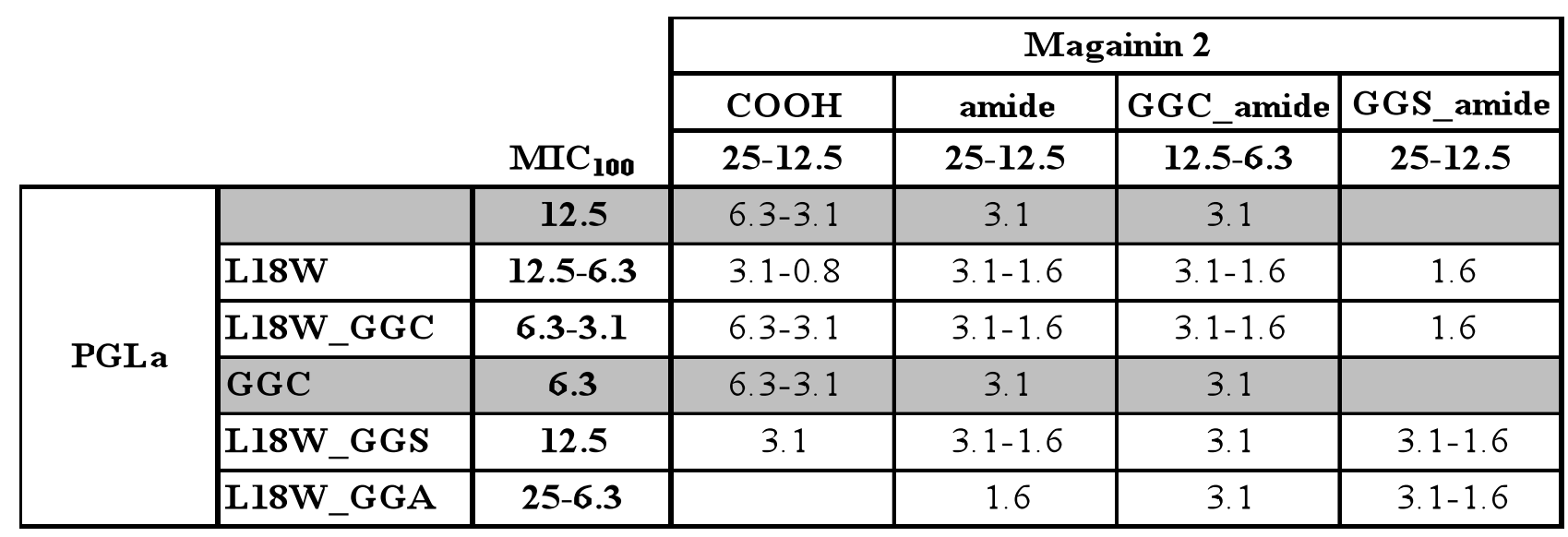




\section{Research Highlights}

PGLa orients parallel to the surface of membranes made from $E$. coli lipids in the absence or presence of magainin 2

Magainin strongly disorders the phopholipid head groups of E. coli lipids

Synergism does not require pronounced direct/covalent peptide-peptide interactions

Lack of correlation between the tendency of PGLa variants to span thin membranes and their synergistic activity. 

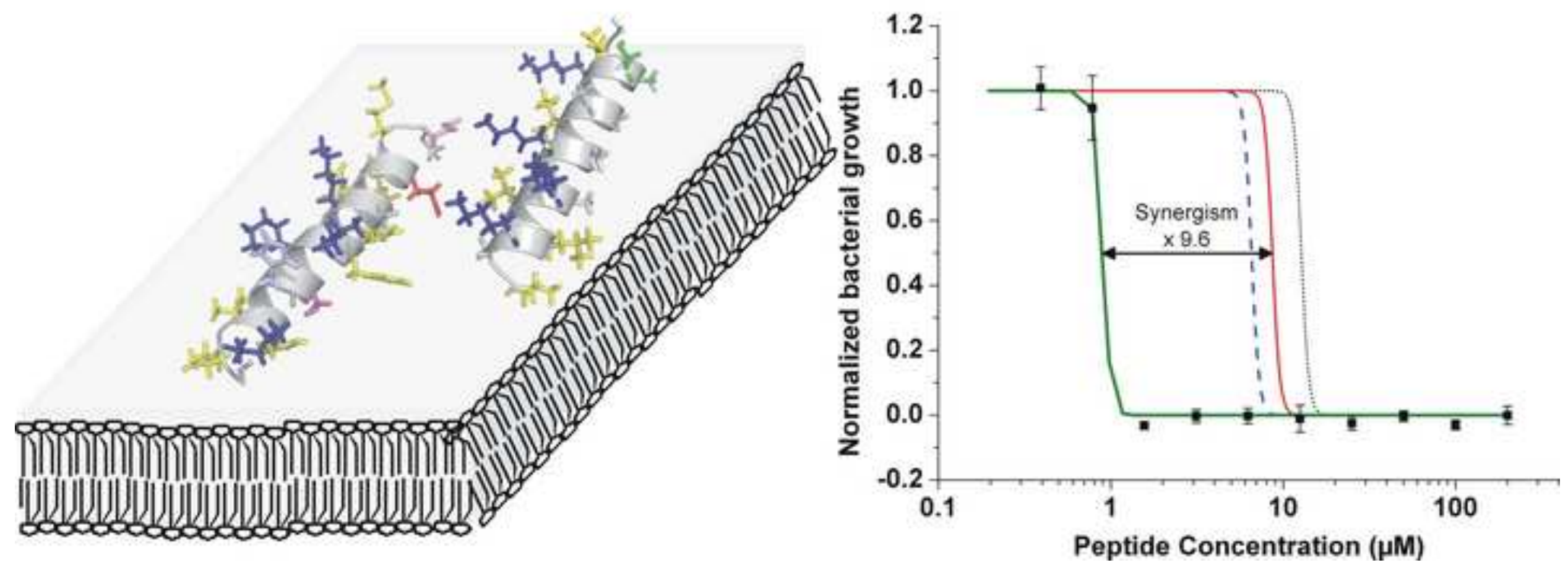